\title{
Effects of Gibberellic Acid and Calcium Chloride on Colour, Phenolic Compounds, Carotenoids and Quality Attributes of White Cabbage (Brassica oleracea) during Storage under Refrigeration
}

Williamson D.D ${ }^{1}$, Benkeblia $\mathrm{N}^{2 *}$

${ }^{1}$ Department of Chemistry, University of the West Indies, Mona Campus, Kingston 7, Jamaica.

${ }^{2}$ Department of Life Sciences, University of the West Indies, Mona Campus, Kingston 7, Jamaica.

\begin{abstract}
The effects of gibberellic acid (150 and $300 \mathrm{mg} / \mathrm{L})$ and calcium chloride $(40 \mathrm{~g} / \mathrm{L})$ on chlorophylls a and b, carotenoids, total phenolic compounds, colour and physiological weight losses of white cabbage (Brassica oleracea L. var. capitata) during storage at $10 \pm 1{ }^{\circ} \mathrm{C}$ were investigated. Results showed that chlorophyll a and total phenolic compounds decreased in all samples and no significant difference was noted between treated heads and control. Chlorophyll $\mathrm{b}$ and carotenoids did not vary much during storage and a steady state was noted in all samples. Treatments maintained well the total colour difference compared to control, and GA treated cabbages maintained better the colour after the fourteen days storage. The chemical treatments also reduced significantly the physiological weight loss which was much greater in controls than in GA treated heads after the storage duration.
\end{abstract}

Keywords: Gibberellic Acid; Calcium Chloride; Refrigeration; Storage; Brassica oleracea.

\section{*Corresponding Author:}

Noureddine Benkeblia,

Department of Life Sciences, University of the West Indies, Mona Campus, Kingston 7, Jamaica.

Tel: +1 8769706849

E-mail: noureddine.benkeblia@uwimona.edu.jm

Received: October 24, 2015

Accepted: December 11, 2015

Published: December 15, 2015

Citation: Williamson D.D, Benkeblia N (2015) Effects of Gibberellic Acid and Calcium Chloride on Colour, Phenolic Compounds, Carotenoids and Quality Attributes of White Cabbage (Brassica oleracea) during Storage under Refrigeration. Int J Food Sci Nutr Diet. 04(7), 239-245. doi: http://dx.doi.org/10.19070/2326-3350-1500043

Copyright: Benkeblia $\mathbf{N}^{\mathcal{O}} 2015$. This is an open-access article distributed under the terms of the Creative Commons Attribution License, which permits unrestricted use, distribution and reproduction in any medium, provided the original author and source are credited.

\section{Introduction}

White Cabbage (Brassica oleracea L. var. capitata) is one of the most commonly cultivated vegetables across the entire island of Jamaica. This crop is cultivated mainly in rural parishes and is a staple food for many Jamaican families. In this context it is customary for the immature leaves within the cabbage head to be consumed while the mature outer leaves are usually rejected. Cabbage as a vegetable contains chlorophylls, carotenoids, vitamins and phenolic compounds that are linked with dietary activities, colour, characteristic flavour and therapeutic value.

Chlorophylls, carotenoids and phenolic compounds are important biological compounds found in all vegetables and contribute to the overall visual quality attributes of cabbage. Degradation of these compounds will lead to quality losses of cabbage heads including yellowing of outer leaves, core elongation, internal yellowing in the apex region, and sometimes in rootlet development at the core-end. These quality defects may affect sales as they are obvious to the consumer when the cabbage has reached market [1]. Gibberellic acid $\left(\mathrm{GA}_{3}\right)$ has been widely used in agriculture. It was reported that $\mathrm{GA}_{3}$ plays a role in the development of colours and metabolic activities in the ripening process of fruits and vegetables, and delays shrivelling and senescence of some fruits [2]. It has also been reported that gibberellic acid reduces physiological weight loss of treated mangoes [3] and lemon [4] during storage.

Calcium chloride is also used to extend the shelf-life of crop commodities [5]. The application of calcium chloride maintains the rigidity of cell walls; and delays membrane lipid catabolism and senescence [6]. Thus, tissues remain firm longer due to the inhibition of many enzymes such as polygalacuturonase which is involved in softening, therefore, ripening is delayed and shelf-life extended $[2,7]$. Many investigations have been conducted on the postharvest application of calcium chloride to extend the shelflife of crops. These have shown that calcium chloride reduces physiological weight loss and delays softening of mangoes [8] and rotting of apples [9] during storage.

Although interesting data exist on the application of gibberellic acid and/or calcium chloride during the pre and the postharvest stages of some commodities, no work reported the application of these two chemicals on cabbage and their potential use to extend the shelf-life of this crop. Therefore, the goal of this study is to investigate the impact of gibberellic acid and calcium chloride on the colour, chlorophylls and carotenoids of cabbage heads during storage under refrigerated temperatures. 


\section{Materials and Methods}

\section{Plant material}

Freshly harvested cabbage heads of uniform size, and free from damage, disease or spoilage, were obtained from the local fresh crops market in Kingston. Cabbages were transported immediately to the laboratory and packed in perforated polyethylene bags. From the total cabbages, fifty were selected and 10 heads per bag were packed and kept few hours at $10 \pm 1^{\circ} \mathrm{C}$ prior to chemical treatments.

\section{Chemicals treatments and storage}

Prior to packaging and storage, cabbages were sprayed six (6) times using spray bottles with the following solutions: gibberellic acid of $150 \mathrm{mg} / \mathrm{L}$ (GA1) and $300 \mathrm{mg} / \mathrm{L}$ (GA2), and calcium chloride $(40 \mathrm{~g} / \mathrm{L})(\mathrm{CC})$. Control samples were sprayed with distilled water. After spraying, samples were left to dry at room temperature, then stored at $10 \pm 1{ }^{\circ} \mathrm{C}$ and $90-95 \% \mathrm{RH}$ during fourteen days.

\section{Chlorophyll a, b and carotenoids assessments}

Chlorophylls a, b and carotenoids are determined according to the method described by Costache et al [10]. One gram of cabbage leaf is homogenised in $50 \mathrm{~mL}$ of $90 \%$ methanol using a mortar and pestle. The homogenate was filtered through two layers of cheesecloth, then centrifuged $1,000 \times \mathrm{g}$ to obtain a clear extract prior to being analysed. The absorbances of the solutions are read at $653 \mathrm{~nm}$ and $666 \mathrm{~nm}$ against $90 \%$ methanol blank.

\section{Determination of total phenolic compounds (TPC)}

Total phenolic compounds were extracted and assayed as described by Singleton and Rossi [11] with some modifications. Samples $(5 \mathrm{~g})$ were homogenized in $70 \%$ ethanol containing $\mathrm{Na}-$ metabisulfite $\left(\mathrm{Na}_{2} \mathrm{~S}_{2} \mathrm{O}_{5}, 20 \mathrm{~g} / \mathrm{L}\right)$ and extracted using an ultrasound assisted extraction (UAE) with an ultra sound sonicator at room temperature. The extracts were centrifuged at $1,000 \times \mathrm{g}$ for 10 min and the supernatant collected for TPC assay. Total phenolic compounds (TPC) of extracts were quantified colorimetrically using Folin-Ciocalteu reagent and chlorogenic acid as standard. Five millilitres of Folin-Ciocalteu (diluted ten-fold in distilled water), 2 $\mathrm{mL}$ of sodium bicarbonate $(200 \mathrm{~g} / \mathrm{L})$ and $2 \mathrm{~mL}$ of distilled water were added to $1 \mathrm{~mL}$ of extract. After $15 \mathrm{~min}$ incubation at room temperature, the absorbance was read at $730 \mathrm{~nm}$ using Thermo Scientific $^{\text {TM }}$ GENESYS 10S UV-VIS spectrophotometer, and results expressed in chlorogenic acid equivalents (mg CAE/g fresh weight).

\section{Colour analysis}

The colour of the arils was measured on the fruit surface using a Konica \& Minolta CR-400 chromameter (Konica \& Minolta Sensing Inc., Osaka, Japan) and the data were expressed in, $L^{*}, a^{*}$ and $b^{*}$ values (CIE). The colour reading was taken in triplicate at the equatorial region of each fruit and averaged to give a value for each cabbage head. The values $a^{*}$ and $b^{*}$ were used to calculate chroma $\left(C^{*}=\left[a^{*} 2+b^{*} 2\right] 1 / 2\right)$, which indicates the intensity or colour saturation, and hue angle $\left(H^{*}=\operatorname{arctangent}\left[\mathrm{b}^{*} / \mathrm{a}^{*}\right]\right)$, where $0^{\circ}=$ red-purple, $90^{\circ}=$ yellow, $180^{\circ}=$ bluish-green, and $270^{\circ}=$ blue [12].

\section{Physiological weight loss (PWL)}

Weight loss was calculated as a percentage (\%) of the initial mass, with an electronic scale. The physiological weight loss was estimated from the difference between the initial and the final weight after each storage period.

\section{Statistical analysis}

Experimental work was duplicated and experiments were run in triplicate. Experimental results were averaged and reported as mean \pm standard deviation (SD). A single factor analysis of variance (ANOVA) was performed using GraphPad Prism 4.03 (GraphPad Software, Inc., 2236 La Jolla, CA, USA). Treatment means were compared by least significant difference (LSD) at $\mathrm{P}$ $\leq 0.05$.

\section{Results and Discussion}

\section{Variation of chlorophylls a, b and carotenoids}

Chlorophyll a varied significantly during storage as shown in Figure 1A. Chlorophyll a decreased significantly in control, CC and GA1 after 11 days storage, while in GA2, the decrease was significant after 14 days storage. After 4 days, chlorophyll a decreased by $46 \%, 27 \%$ and $50 \%$ in control, CC and GA1, respectively, and the decrease reached $81 \%, 76 \%$ and $81 \%$ after 14 days storage, respectively. In GA2 treated cabbage, chlorophyll a decreased by $12 \%$ after four days, but the decrease was similar to that observed in other treated cabbage and reached $80 \%$.

Surprisingly, chlorophyll b in cabbage did not show significant variation during storage (Figure 1B). Chlorophyll b varied from an initial value of $2.49 \mathrm{mg} / \mathrm{g}$ DW and averaged 2.53, 2.56 and $2.63 \mathrm{mg} / \mathrm{g} \mathrm{DW}$ after four, eleven and fourteen days storage, respectively. Similarly, total carotenoids decreased slightly but did not vary significantly in cabbage during storage (Figure 1C). Total carotenoids yielded $2.71 \mathrm{mg} / \mathrm{g}$ DW in fresh cabbage heads, and decreased by $14 \%, 3 \%, 15 \%$ and $4 \%$ in control, CC, GA1 and GA2 after fourteen days storage, respectively. On the other hand, carotenoids in cabbage averaged 2.62, 2.55 and $2.46 \mathrm{mg} / \mathrm{g}$ DW after four, eleven and fourteen days, respectively.

Comparatively, chlorophylls a/b ratio was estimated and data showed the ratio decreased progressively from 0.31 to $0.17,0.22$, 0.15 and 0.28 after four days, to $0.13,0.07,0.15$ and 0.16 after eleven days, and to 0.06, 0.07, 0.06 and 0.06 after fourteen days in control, CC, GA1 and GA2, respectively (Figure 2A). On the other hand, the chlorophylls $[\mathrm{a}+\mathrm{b}] /$ carotenoids ratio varied very slightly and decreased from 1.20 to $1.21,1.21,1.07$ and 1.17 after four days, to $1.18,1.07,1.15$ and 1.11 after eleven days, and to 1.19, 1.09, 1.19 and 1.07 after fourteen days in control, CC, GA1 and GA2, respectively (Figure $2 \mathrm{~B}$ ).

The use of gibberellic acid as a preharvest treatment is extensively documented. While the postharvest treatment reported is mainly on the use of GA to extend the shelf-life and longevity of ornamental flowers, few reports are available on fruits and vegetables. However, some discrepancies have been reported on the effect of postharvest application of GA on chlorophyll content. Siddiqui et al [13] reported a decrease of c.a. $50 \%$ in chlorophylls of mango fruits stored twelve days at room temperature of $28 \pm 2{ }^{\circ} \mathrm{C}$, and no difference in effect was noted between the different GA con- 
Figure 1. Chlorophylls a(A), chlorophylls b(B) and carotenoids (C) concentration in cabbage heads stored at $10 \pm 1^{\circ} \mathrm{C}$ during 14 days. $\square$ Control, $\quad$ Calcium Chloride, GA1 $\square$ GA2

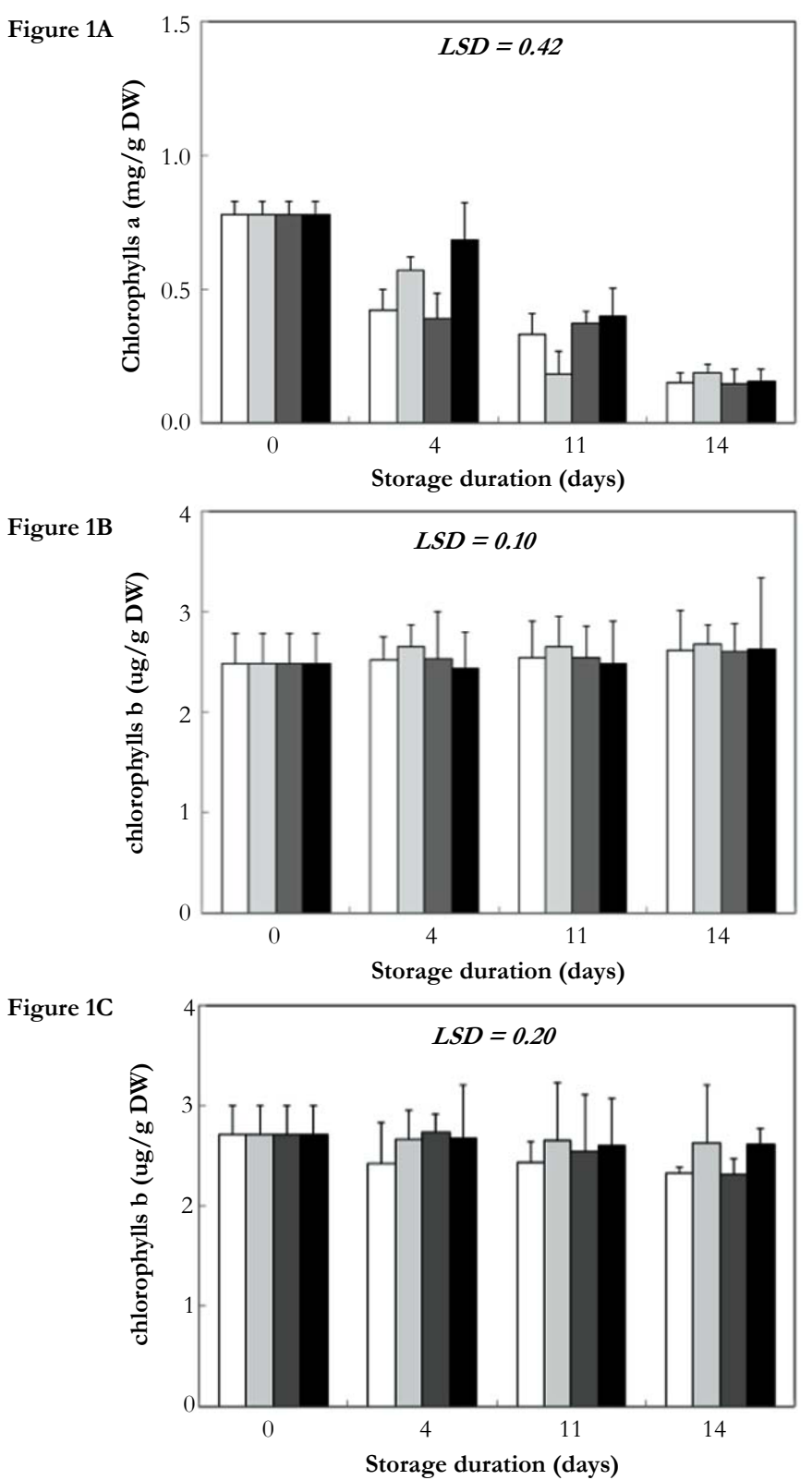

Figure 2. Chlorophylls a/b (A) and Chlorophylls a+b/carotenoids (B) ratios in cabbage heads stored at $10 \pm 1^{\circ} \mathrm{C}$ during 14 days. Control, $\triangle$ Calcium Chloride, O GA1. $\square$ GA2
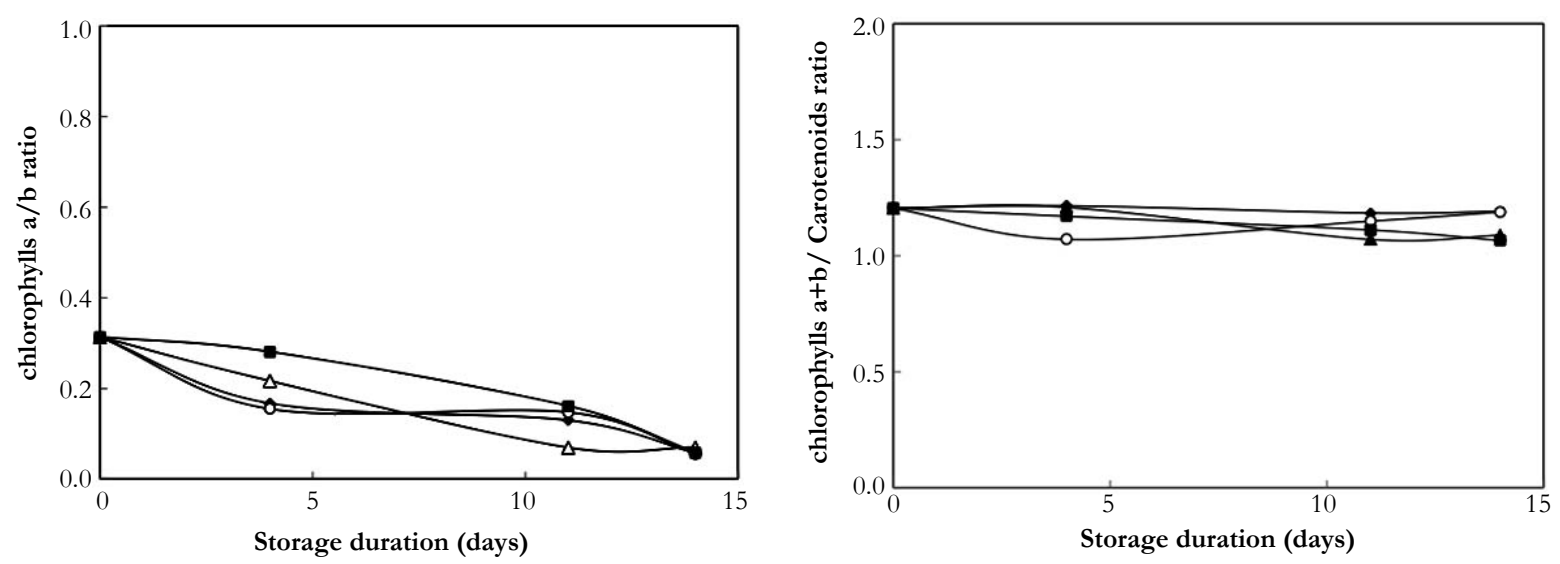
centrations used.

On the contrary, many studies reported that GA retained green colour of fruits and chlorophylls. Gross et al [14] reported that GA treatments delayed the senescence and retained chlorophyll in persimmon for long periods. Pre and postharvest applications of GA also retained the green fruit colour of citrus fruits. Mahajan et al [7] used different concentrations of $\mathrm{GA}_{3}$ ranging from 25 to $75 \mathrm{ppm}$ on guava fruit and no significant difference in effect was noted among these concentrations. Singh and Dankhar [15] reported that postharvest application of GA retained chlorophylls in okra during storage and retention was higher even with visible senescence. They also noted that chlorophyll a decreased more rapidly than chlorophyll b which surprisingly exceeded the content of chlorophyll a in some fruits.

Janowska and Jerzy [16] investigated the effects of GA on the longevity of Zantedeschia elliottiana leaves and noted that GA reduced the degradation of chlorophylls, but no significance was noted between the concentrations and exposure time. Indeed, the mechanisms of GA on chlorophylls are not clearly understood, but it is likely that GA delays the activity of chlorophyllase during ripening of GA treated strawberry fruit as reported by Martínez et al [17], and/or promotes chlorophyll synthesis [14]. Indeed, the visible colour of plants results from the predominant pigments, even though other pigments are present but are not visible unless the predominant is degraded. Consequently, the degradation of chlorophylls causes colours change in the tissues from green to many other colours such as yellow and orange observed in ripe and senescent tissues [18].

Calcium chloride is widely used in agriculture and food preservation as well. Investigations showed that postharvest use of calcium chloride maintains firmness and visual quality, therefore, extending the shelf life of the fresh produce. It was reported that dipping fruits in calcium chloride was effective in delaying senescence and extended figs [19] and jujube [20] shelf-life during storage. On the other hand, calcium chloride treatments have also been reported as effective in reducing chlorophyll [21]. Calcium chloride has also been used in combination with gibberellic acid and other organic acids. Bhanja and Lenka [22] combined gibberellic acid and calcium chloride treatments of sapota (Achraszapota) fruit, and they noted that treatments reduced the physiological weight losses and percentage rotting of fruits during storage, and the shelf-life was extended to 36 days compared to control (8 days).

Indeed, these results are not in contradiction with our results, as we noted that chlorophyll a content is much lower than chlorophyll b. Even though chlorophyll a decreased chlorophyll b did not vary much, therefore, making the change in total chlorophylls $(\mathrm{a}+\mathrm{b})$ not significant as shown in Figure 2.

\section{Variation of total phenolics content (TPC)}

The total phenolics content decreased progressively during storage of cabbage heads, however, the decrease was significant in the control after four days, while in GA2 TPC decreased significantly after fourteen days (Figure 3). After four days, TPC decreased from 50.91 to $40.20,39.97,45.13$ and $47.26 \mathrm{mg} / \mathrm{g}$ DW in control, CC, GA1 and GA2, respectively. After fourteen days storage, TPC decreased significantly to 26.17, 26.38, 28.91 and 27.10 $\mathrm{mg} / \mathrm{g}$ DW in control, CC, GA1 and GA2, respectively, and no significant difference was noted between control and treatments.

Many investigations have reported on TPC of white cabbage heads, and different TPC has been determined. For example and among literature cited, Leja et al [23] reported values ranging between 12.58 and $47.6 \mathrm{mg} \mathrm{GAE} / 100 \mathrm{~g} \mathrm{FW}$. The large variations of TPC in white cabbages vary with different factors such as the botanical cabbage group [24], variety [25], extraction solvents used [26], and growing region [27].

Many works reported on the total phenolics of cabbage, but few exist on the variation of TPC during storage, and no work reports on the effects of GA and calcium chloride on TPC in stored cabbage. Hounsome et al [28] studied the variation of different phenolic compounds during storage and they noted that longterm storage significantly reduced the content of many phenolic compounds such as caffeic, syringic, gallic and trihyroxybenzoic acids, as well as flavonoids, while other phenolics such as cinnamic, dimethoxybenzoic acid, chalcone and flavone were less affected by storage. Hagen et al [29] stored another Brassica variety called curly kale (Brassica oleracea L. var. acephala) and noted that total phenolics increased slightly after six weeks storage at $1^{\circ} \mathrm{C}$. Nevertheless, in stored lettuce, escarole and rocket salad tissues, TPC varied differently. TPC increased after one day but decreased after three days storage at $4^{\circ} \mathrm{C}$. In escarole, TPC increased significantly after three days, while in rocket tissues TPC decreased after three days at the same temperature [30].

\section{Colour variation}

During storage, colour of cabbage heads showed different variations (Table 1). Data of $a^{*}$ are indicating that cabbage heads are less after eleven days storage, and the lightness decreased after the same storage period as indicated by the decrease of $L^{*}$. The $b^{*}$ decreased from positive to negative values and the $H^{*}$ increased after fourteen days storage indicating that the yellowish colour of cabbages is decreasing and the heads are turning darker and did not retain the yellow colour (as shown in Figure 5). However, no significant difference was noted between control and treated cabbages during the storage period.

Moreover, the total colour difference between all three coordinates was determined by the following equation:

$$
\Delta E=\sqrt{ }\left(\Delta L^{2}+\Delta a^{2}+\Delta b^{2}\right)
$$

Data are showing that control, CC, GA1 and GA2 averaged 12.00, 25.56, 24.69 and 22.92 after four, eleven and fourteen days storage indicating that the colour of control and GA2 are lighter than CC and GA1.

Few works have reported on the variation on colour of cabbage during storage, while no reference is readily available on the effects of gibberillic acid and calcium chloride on stored cabbage heads. Manolopoulou and Varzakas [31] reported similar results and noted that lightness $L^{*}$ and $H^{*}$ values of fresh cabbage stored at $0^{\circ} \mathrm{C}$ decreased after 15 days storage, but $L^{*}$ decreased after 20 days storage, and these data are in agreement with our results indicating that the reduction was limited regardless of the chemical treatments and the initial colour was to some extent preserved. The increase of $H^{*}$ value observed after fourteen days might be due to browning caused by the senescence [32]. On the other hand, it was suggested that the total colour difference $(\Delta \mathrm{E})$ could 
Figure 3. Total phenolic compounds concentration in cabbage heads stored at $10 \pm 1^{\circ} \mathrm{C}$ during 14 days. For legends see Figure 1.

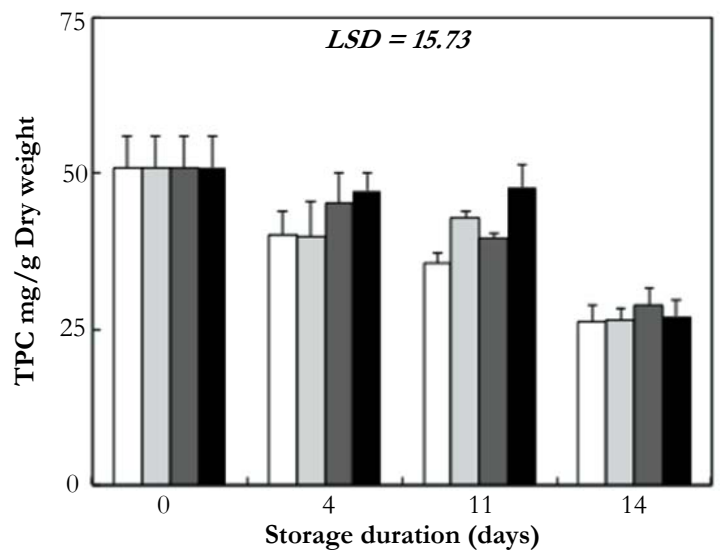

Figure 4. Weight losses in cabbage heads stored at $10 \pm 1^{\circ} \mathrm{C}$ during 14 days. For legends see Figure 1.

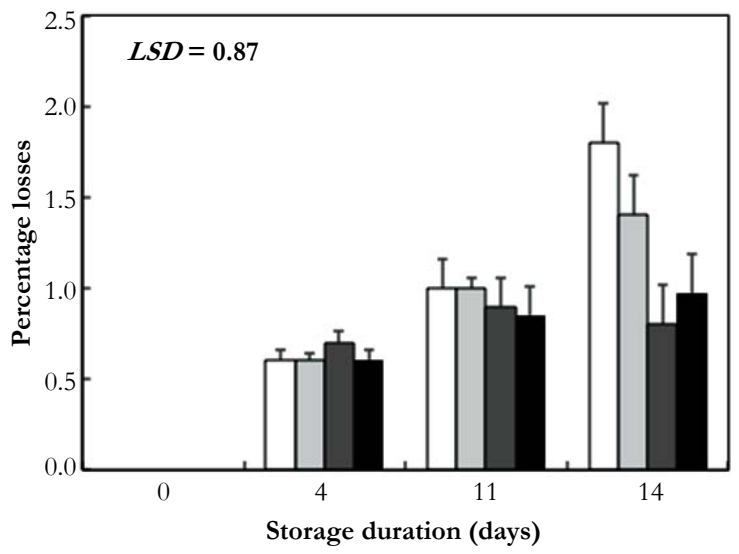

Figure 5. Cabbage heads stored at $10 \pm 1^{\circ} \mathrm{C}$ during 14 days.

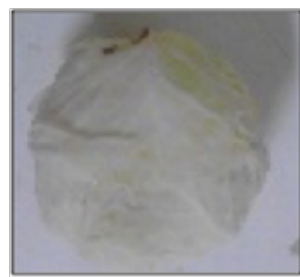

\section{Control}
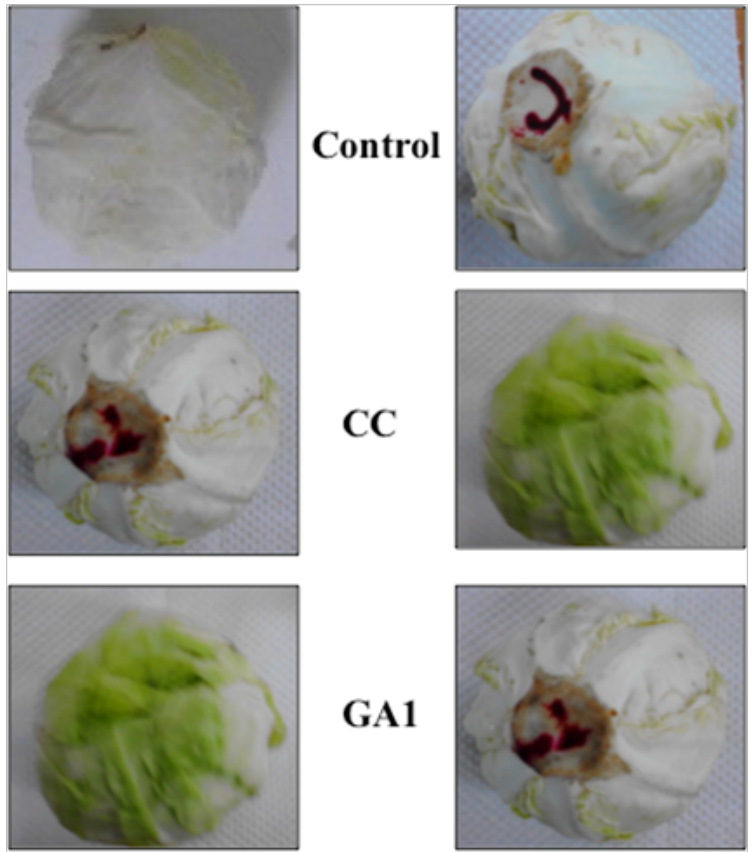

\section{GA1}
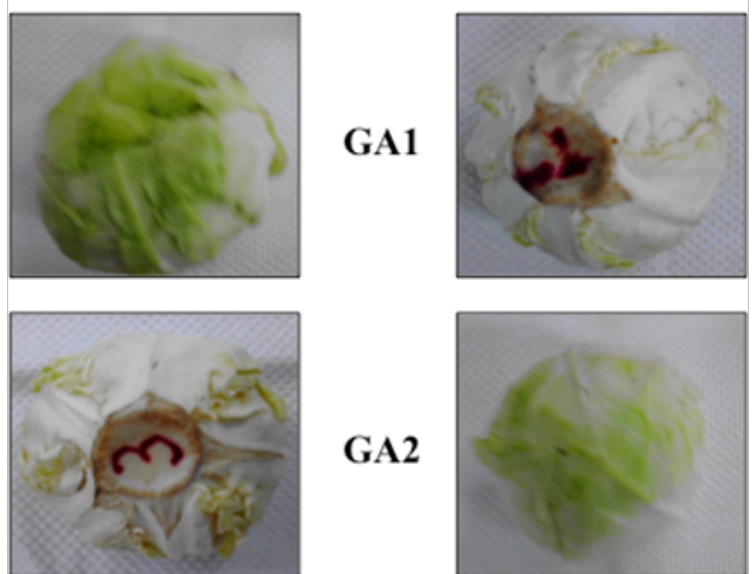

GA2

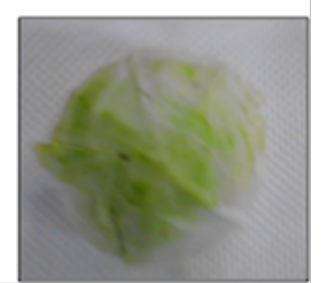


Table 1. Variation of colour parameters of cabbage heads during storage. Values with different superscript letters within the same columns are significantly different.

\begin{tabular}{|c|c|c|c|c|c|}
\hline \multirow{2}{*}{} & $a^{*}$ & $b^{*}$ & $L^{*}$ & $C^{*}$ & $H^{*}$ \\
\cline { 2 - 6 } & \multicolumn{5}{|c|}{ Freshly harvested } \\
\cline { 2 - 6 } & $70.60 \pm 2.90$ & $10.46 \pm 0.30$ & $31.94 \pm 1.97$ & $33.62 \pm 1.90$ & $108.23 \pm 1.02$ \\
\cline { 2 - 6 } & \multicolumn{5}{|c|}{ After 4 days storage at $10 \pm 1^{\circ} \mathrm{C}$} \\
\hline Control & $70.60 \pm 2.90^{\mathrm{a}}$ & $10.46 \pm 0.30^{\mathrm{a}}$ & $31.94 \pm 1.97^{\mathrm{a}}$ & $33.62 \pm 1.90^{\mathrm{a}}$ & $108.23 \pm 1.02^{\mathrm{a}}$ \\
\hline CC & $69.66 \pm 6.54^{\mathrm{a}}$ & $11.14 \pm 0.86^{\mathrm{b}}$ & $25.98 \pm 1.35^{\mathrm{b}}$ & $28.30 \pm 1.33^{\mathrm{b}}$ & $113.26 \pm 9.78^{\mathrm{a}}$ \\
\hline GA1 & $70.28 \pm 3.94^{\mathrm{a}}$ & $14.25 \pm 0.74^{\mathrm{b}}$ & $30.70 \pm 2.07^{\mathrm{a}}$ & $33.85 \pm 2.17^{\mathrm{a}}$ & $114.96 \pm 0.60^{\mathrm{a}}$ \\
\hline GA2 & $72.44 \pm 2.68^{\mathrm{a}}$ & $9.63 \pm 4.85^{\mathrm{a}}$ & $28.61 \pm 3.87^{7 \mathrm{~b}}$ & $35.25 \pm 2.27^{\mathrm{a}}$ & $123.59 \pm 6.96^{\mathrm{b}}$ \\
\hline & \multicolumn{5}{|c|}{ After 11 days storage at $10 \pm 1{ }^{\circ} \mathrm{C}$} \\
\hline Control & $58.16 \pm 7.75^{\mathrm{b}}$ & $-10.63 \pm 1.16$ & $18.94 \pm 2.01^{\mathrm{c}}$ & $24.26 \pm 2.12^{\mathrm{b}}$ & $113.05 \pm 2.22^{\mathrm{a}}$ \\
\hline CC & $61.79 \pm 5.96^{\mathrm{b}}$ & $-13.61 \pm 1.11$ & $30.96 \pm 1.67^{\mathrm{a}}$ & $33.83 \pm 1.98^{\mathrm{b}}$ & $113.67 \pm 8.55^{\mathrm{a}}$ \\
\hline GA1 & $57.47 \pm 8.04^{\mathrm{b}}$ & $-9.96 \pm 1.07$ & $22.90 \pm 1.94^{\mathrm{b}}$ & $24.99 \pm 2.10^{\mathrm{b}}$ & $113.47 \pm 7.10^{\mathrm{a}}$ \\
\hline GA2 & $49.76 \pm 7.53^{\mathrm{c}}$ & $-13.75 \pm 3.44$ & $27.17 \pm 6.05^{5 \mathrm{~b}}$ & $30.46 \pm 6.94^{\mathrm{ab}}$ & $126.42 \pm 11.4^{\mathrm{b}}$ \\
\hline & \multicolumn{5}{|c|}{ After 14 days storage at $10 \pm 1{ }^{\circ} \mathrm{C}$} \\
\hline Control & $70.60 \pm 2.90^{\mathrm{a}}$ & $10.46 \pm 0.30$ & $19.94 \pm 1.97^{\mathrm{a}}$ & $23.62 \pm 1.90^{\mathrm{b}}$ & $116.23 \pm 1.02^{\mathrm{a}}$ \\
\hline CC & $63.36 \pm 3.02^{\mathrm{b}}$ & $-12.85 \pm 2.28$ & $24.37 \pm 1.66^{\mathrm{b}}$ & $27.61 \pm 2.50^{\mathrm{ab}}$ & $117.29 \pm 2.86$ \\
\hline GA1 & $71.82 \pm 6.08^{\mathrm{a}}$ & $-13.20 \pm 1.53$ & $24.99 \pm 3.57^{\mathrm{b}}$ & $28.26 \pm 5.72^{\mathrm{ab}}$ & $117.84 \pm 9.72$ \\
\hline GA2 & $72.72 \pm 2.54^{\mathrm{a}}$ & $-10.63 \pm 1.20$ & $23.21 \pm 1.72^{\mathrm{b}}$ & $25.55 \pm 2.01^{\mathrm{b}}$ & $124.50 \pm 13.5^{\mathrm{b}}$ \\
\hline
\end{tabular}

be used as a discoloration index [33], and our data are suggesting that all treatments did not preserve the colour of cabbage.

\section{Physiological weight loss (PWL)}

During storage, PWL increased progressively during storage, however, control and CC treated cabbages showed higher PWL than GA treated ones (Figure 4). After four days storage, PWL averaged $0.6 \%$ to $0.7 \%$ in control and treated cabbages, and after eleven days PWL averaged $1.00 \%, 1.00 \%, 0.90 \%$ and $0.85 \%$ in control, CC, GA1 and GA2, respectively, with no significant difference between control and all treated cabbages. Nevertheless, after fourteen days storage, PWL averaged 1.80\%, 1.40\%, 0.80\% and $0.97 \%$ in control, CC, GA1 and GA2, respectively. By fitting linear regression lines to weight losses vs time, results showed average losses of $0.13 \%, 0.11 \%, 0.06 \%$ and $0.07 \%$ per day in control, CC, GA1 and GA2, respectively, indicating that GA treatment was more efficient in reducing PWL than CC treatment.

Extensive literature exists on PWL of fresh crops during storage. Weigh losses of fresh crops is the consequence of respiration and oxidative reactions, mainly sugars. However, degradation of energy-source compounds is correlated to many factors such as the physiological stage, temperatures and storage duration, as well as other factors such as gas composition (eg., modified atmosphere packaging), and even the microbial charge of the stored crops [34]. Manolopoulou and Varzakas [31] reported that weight losses of cabbage averaged 3\% after twenty-three days storage at $4^{\circ} \mathrm{C}$. In minimally processed cabbage, weight losses were higher and averaged $2.81 \%$ and $3.32 \%$ in control, and $2.28 \%$ and $3.35 \%$ in calcium chloride treated heads stored during twenty-two days at $0^{\circ} \mathrm{C}$ and $5^{\circ} \mathrm{C}$, respectively [35].

\section{Conclusions}

The application of gibberellic acid and calcium chloride to extend the shelf-life of cabbage heads stored under refrigeration showed that these chemical treatments did not reduce chlorophyll a and total phenolic compounds losses but maintained chlorophyll b and carotenoid levels which contributed to better colour preservation although no statistical difference was noted. However, all the chemical treatments reduced significantly the physiological weight losses which were much higher in the control. We can conclude that gibberellic acid and calcium chloride could be used to maintain the quality attributes of fresh cabbage heads stored under refrigerated temperature, however, the optimal storage period should not exceed two weeks.

\section{Acknowledgements}

This work was supported by a New Research Initiative Research Grant from the Office of the Graduate Studies \& Research, UWI, Mona.

\section{References}

[1]. Kramchote S, Srilaong V, Wongs-Aree C, Kanlayanarat S (2012) Low temperature storage maintains postharvest quality of cabbage (Brassica oleraceae var. capitata L.) in supply chain. Int Food Res J 19(2): 759-763.

[2]. Pila N, Gol NB, Rao TVR (2010) Effect of post-harvest treatments on physicochemical characteristics and shelf life of tomato (Lycopersicon esculentum Mill.) fruits during storage. Am Eurasian J Agric Environ Sci 9(5): 470-479.

[3]. Ahmed MS, Sanjay S (1999) Effect of various post-harvest treatments on shelf-life of amrapali mango. Orrisa J Hortic 27: 29-33.

[4]. Sindhu SS, Singhrot RS (1993) Effect of Pre-harvest spray of growth regulator and fungicides on the shelf life of lemon cv. Baramasi-A note. Haryana J Hort Sci 22: 204-204.

[5]. Martín-Diana AB, Rico D, Frías JM, Barat JM, Henehan G, et al. (2007) Calcium for extending the shelf life of fresh whole and minimally processed fruits and vegetables: a review. Trends Food Sci Technol 18(4): 210-218.

[6]. Ferguson IB (1984) Calcium in plant senescence and fruit ripening. Plant Cell Environ 7(6): 477-489.

[7]. Mahajan BVC, Ghuman BS, Bons HK (2011) Effect of postharvest treatment of calcium chloride and gibberellic acid on storage behaviour and quality of guava fruits. J Hort Sci Ornamen Plants 3: 38-42.

[8]. Mootoo A (1991) Effect of post-harvest calcium chloride dips on ripening 
changes in 'Julie' mangoes. Trop Sci 31(3): 243-248.

[9]. Nayital RK, Chopra SK, Sharma YP (1990) Effect of post-harvest application of calcium chloride, fungicides and wax emulsion on the storage behaviour of apple cv. red delecious. Indian Food Packer 44: 31-38.

[10]. Costache MA, Campeanu G, Neata G (2012) Studies concerning the extraction of chlorophyll and total Carotenoids from vegetables. Romanian Biotechnol Lett 17(5): 7702-7708.

[11]. Singleton VL, Rossi Jr JA (1965) Colorimetry of total phenolics with phosphomolybdic-phosphotungstic acid reagents. Am J Enol Vitic 16(3): 144158.

[12]. McGuire RG (1992) Reporting of objective color measurements. Hort Science 27(12): 1254-1255.

[13]. Siddiqui MW, Dutta P, Dhua RS, Dey A (2014) Changes in biochemical composition of mango in response to pre-harvest gibberellic acid spray. Agric Consp Sci 78(4): 331-335.

[14]. Gross J, Bazak H, Blumenfeld A, Ben-Arie R (1984) Changes in chlorophyll and carotenoid pigments in the peel of Triumph persimmon (Diospyros kaki L.) induced by pre-harvest gibberellin (GA3) treatment. Sci Hort 24(3-4): 305-314.

[15]. Singh BP, Dhankhar BS (1980) Effect of growth regulators and pre-packaging on the storage life of okra. Haryana Agric Univ J Res 10(3): 398-402.

[16]. Janowska B, Jerzy M (2003) Effect of gibberellic acid on the post-harvest leaf longevity of Zantedeschia elliottiana (W. Wats.) Engl. J Fruit Ornam Plant Res 11: 69-76.

[17]. Martínez GA, Chaves AR, Añón MC (1996) Effect of exogenous application of gibberellic acid on color change and phenylalanine ammonia-lyase, chlorophyllase, and peroxidase activities during ripening of strawberry fruit (Fragaria x ananassa Duch.). J Plant Growth Regul 15: 139-146.

[18]. Schoefs B (2002) Chlorophyll and carotenoid analysis in food products. Properties of the pigments and methods of analysis. Trends Food Sci Technol 13(11): 361-371.

[19]. Irfan PK, Vanjakshi V, Prakash KMN, Ravi R, Kudachikar VB (2013) Calcium chloride extends the keeping quality of fig fruit (Ficus carica L.) during storage and shelf-life. Postharvest Biol Technol 82: 70-75.

[20]. Li L, Ban Z, Li X, Xue T (2014) Effect of 1-methylcyclopropene and calcium chloride treatments on quality maintenance of 'Lingwu Long' jujube fruit. J Food Sci Technol 51(4): 700-707.

[21]. Smout C, Sila DN, Vu TS, Van Loey A, Hendrickx M (2005) Effect of preheating and calcium pre-treatment on pectin structure and thermal texture degradation: a case study on carrots. J Food Eng 67(4): 419-425.
[22]. Bhanja PK, Lenka PC (1994) Effect of pre- and postharvest treatments on storage life of sapota fruits cv. Oval. Orissa J Hort 22(1): 54-57.

[23]. Leja M, Kamińska I, Kołton A (2010) Phenolic compounds as the major antioxidants in red cabbage. Folia Hort 22(1): 19-24.

[24]. Cartea ME, Francisco M, Soengas P, Velasco P (2011) Phenolic compounds in brassica vegetables. Molecules 16(1): 251-280.

[25]. Singh J, Upadhyay AK, Bahadur A, Singh B, Singh KP, et al. (2006) Antioxidant phytochemicals in cabbage (Brassica oleracea L. var. capitata). Sci Hort 108(3): 233-237.

[26]. Podsedek A (2007) Natural antioxidants and antioxidant capacity of Brassica vegetables: A review. LWT/Food Sci Technol 40(1): 1-11.

[27]. Kusznierewicz B, Bartoszek A, Wolska L, Drzewiecki J, Gorinstein S, et al. (2008) Partial characterization of white cabbages (Brassica oleracea var. capitata $\mathrm{f}$. alba) from different regions by glucosinolates, bioactive compounds, total antioxidant activities and proteins. LWT/Food Sci Technol 41(1): 1-9.

[28]. Hounsome N, Hounsome B, Tomos D, Edwards-Jones G (2009) Changes in antioxidant compounds in white cabbage during winter storage. Postharvest Biol Technol 52(2): 173-179.

[29]. Hagen SF, Borge GIA, Solhaug KA, Bengtsson GB (2009) Effect of cold storage and harvest date on bioactive compounds in curly kale (Brassica oleracea L. var. acephala). Postharvest Biol Technol 51: 36-42.

[30]. Degli'innoocenti E, Pardossi A, Tattini M, Guidi L (2008) Phenolic compounds and antioxidant power in minimally processed salad. J food Biochem 32(5): 642-653.

[31]. Manolopoulou E, Varzakas TH (2013) Effect of modified atmosphere packaging (MAP) on the quality of 'ready-to-eat' shredded cabbage. Int J Agric Food Res 2(3): 30-43.

[32]. Kaji H, Ueno M, Osajima Y (1993) Storage of shredded cabbage under a dynamically controlled atmosphere of high oxygen and high carbon dioxide. Biosci Biotechnol Biochem 57(7): 1049-1052.

[33]. Hu W, Jiang A, Qi H, Pang K, Fan S (2007) Effects of initial low oxygen and perforated film package on quality of fresh-cut cabbage. J Sci Food Agric 87(11): 2019-2025.

[34]. Paull RE (1999) Effect of temperature and relative humidity on fresh commodity quality. Postharvest Biol Technol 15(3): 263-277.

[35]. Manolopoulou E, Varzakas T (2011) Effect of storage conditions on the sensory quality, colour and texture of fresh-cut minimally processed cabbage with the addition of ascorbic acid, citric acid and calcium chloride. Food Nutri Sci 2(9): 956-963. 